\title{
Transcript Profiles of Blumeria graminis Development During Infection Reveal a Cluster of Genes That Are Potential Virulence Determinants
}

\author{
Maike Both, ${ }^{1}$ Sabine E. Eckert, ${ }^{1}$ Michael Csukai, ${ }^{2}$ Elisabeth Müller, ${ }^{2}$ George Dimopoulos, ${ }^{3}$ and \\ Pietro D. Spanu ${ }^{1}$ \\ ${ }^{1}$ Department of Biological Sciences, Sir Alexander Fleming Building, Imperial College Rd, Imperial College London, \\ London, SW7 2AZ, U.K.; '2Syngenta Ltd, Jealott's Hill International Research Centre, Bracknell, Berkshire, RG42 6ET, U.K.; \\ ${ }^{3}$ Department of Molecular Microbiology and Immunology, Malaria Research Institute, Bloomberg School of Public Health, \\ Johns Hopkins University, 615 N. Wolfe Street, Baltimore, MD 21205-2179, U.S.A.
}

Submitted 21 July 2004. Accepted 4 October 2004.

\begin{abstract}
High-density cDNA microarrays $(2,027$ unigenes) were used to analyze transcript profiles of the plant-pathogenic fungus Blumeria graminis f. sp. hordei throughout its asexual life cycle and development of infection. RNA was obtained from four stages preceding penetration and four stages after penetration of the host cells. The microarray data was validated by comparing the expression of a plasma membrane $\mathrm{H}^{+}$ATPase and fructose-1,6-bis phosphatase with the data obtained from a quantitative polymerase chain reaction (PCR) assay. The results showed that there was a global switch in expression between the pre- and postpenetrative stages. This was largely due to accumulation of RNA encoding protein biosynthesis genes in the late stages. Other functional clusters, such as virulence-related genes and sterol metabolism genes, are up-regulated in pre- and postpenetration stages, respectively. A group of RNAs whose abundance correlated with the expression of cap20, a gene known to be required for virulence in Colletotrichum gloeosporioides, identified genes that are strong candidates for pathogenicity factors in B. graminis.
\end{abstract}

Blumeria graminis f. sp. hordei causes powdery mildew on barley (Bélanger et al. 2002). Like all powdery mildews, $B$. graminis is an obligate biotrophic pathogen that requires a living host to complete its life cycle. Powdery mildews of cereals are some of the most common pathogens in northern European agriculture and are kept at bay effectively, thanks to the deployment of resistant crop cultivars and extensive use of fungicides (Hewitt 1998).

The asexual life cycle of $B$. graminis on an appropriate host follows a highly controlled and synchronous development (Both and Spanu 2004); once a conidium lands on the leaf, it produces within an hour a short primary germ tube that senses the nature of the surface (Kinane et al. 2000). This is followed by the germination of a secondary germ tube that eventually swells slightly and develops into a hooked appressorium. A combination of enzymatic degradation of the host cell wall and a high turgor pressure generated in the appressorium enables a hyphal

Corresponding author: P. D. Spanu; Telephone: +44-20-75945384; Fax: +44-20-75842056; E-mail: p.spanu@imperial.ac.uk

Current address of S. E. Eckert: Department of Biosciences, University of Kent at Canterbury, Canterbury, CT2 7NY, U.K. peg to penetrate the epidermal cell beneath the appressorium (Francis et al. 1996; Pryce-Jones et al. 1999). Inside the epidermal cell, B. graminis produces a haustorium, the structure devoted to nutrient uptake. When a functional haustorium is in place, the epiphytic mycelium proliferates and produces further secondary appressoria, which then form additional haustoria. After about 3 days postinoculation (dpi), the colonies are visible to the naked eye on the leaf surface, and from then on, conidiophores emerge to produce large masses of asexual conidia that disseminate the fungus to other host plants.

Initial research into understanding the molecular basis for development and pathogenicity in $B$. graminis has centered on expressed sequence tag (EST) sequencing of cDNA libraries synthesized from ungerminated and germinated conidia (Thomas et al. 2001). Serial analysis of gene expression has been carried out on the early stages of development from conidia to the formation of appressoria (Thomas et al. 2002). In addition to this, the expression of a number of individual genes has been studied using a combination of semiquantitative polymerase chain reaction (PCR) and RNA gel blot analysis (Grell et al. 2003; Kinane and Oliver 2003; Zhang and Gurr 2001; Zhang et al. 2001).

In this paper, we describe a survey of transcript profiles using cDNA microarrays of 2,027 B. graminis genes during the infection cycle. The samples were collected from eight stages of development, from germination of the conidia on the leaf surface to the production of new conidia five dpi. We also included an analysis of the transcript abundance in the infected epidermis 3 and $5 \mathrm{dpi}$. We verified the validity of the results obtained by analyzing the variability between independent samples, by comparing the microarray results with quantitative real-time PCR, and by consistency with data available in the published literature. The overall results revealed a large-scale shift in gene expression between the pre- and postpenetrative stages of development. We identified a cluster of genes whose expression profiles correlated with those of known determinants of pathogenicity in other plant-pathogenic fungi. We propose that these genes are candidates for genes promoting virulence and pathogenicity in B. graminis.

\section{RESULTS}

Blumeria cDNA microarrays.

The cDNAs were obtained from three separate libraries. EST sequences of cDNAs from conidia (library D) and germi- 
nating conidia (library C), representing 1,669 unigenes, had been previously characterized in the Carlsberg laboratory (Denmark) (Thomas et al. 2001); the respective clones are held in the Consortium for the functional Genomics of Microbial Eukaryotes (COGEME) collection. A third library contained 499 cDNA clones representative of RNA expressed by the mycelium that grows on the surface of the infected barley leaves prior to the onset of massive conidiation; of these, 328 were novel and were not present in the conidial libraries. A total of 3,327 cDNAs from the three libraries representing 2,027 unigenes were spotted in duplicate on derivatized glass slides. EST sequence information is available for all of these clones in publicly accessible databases. We isolated RNA from eight
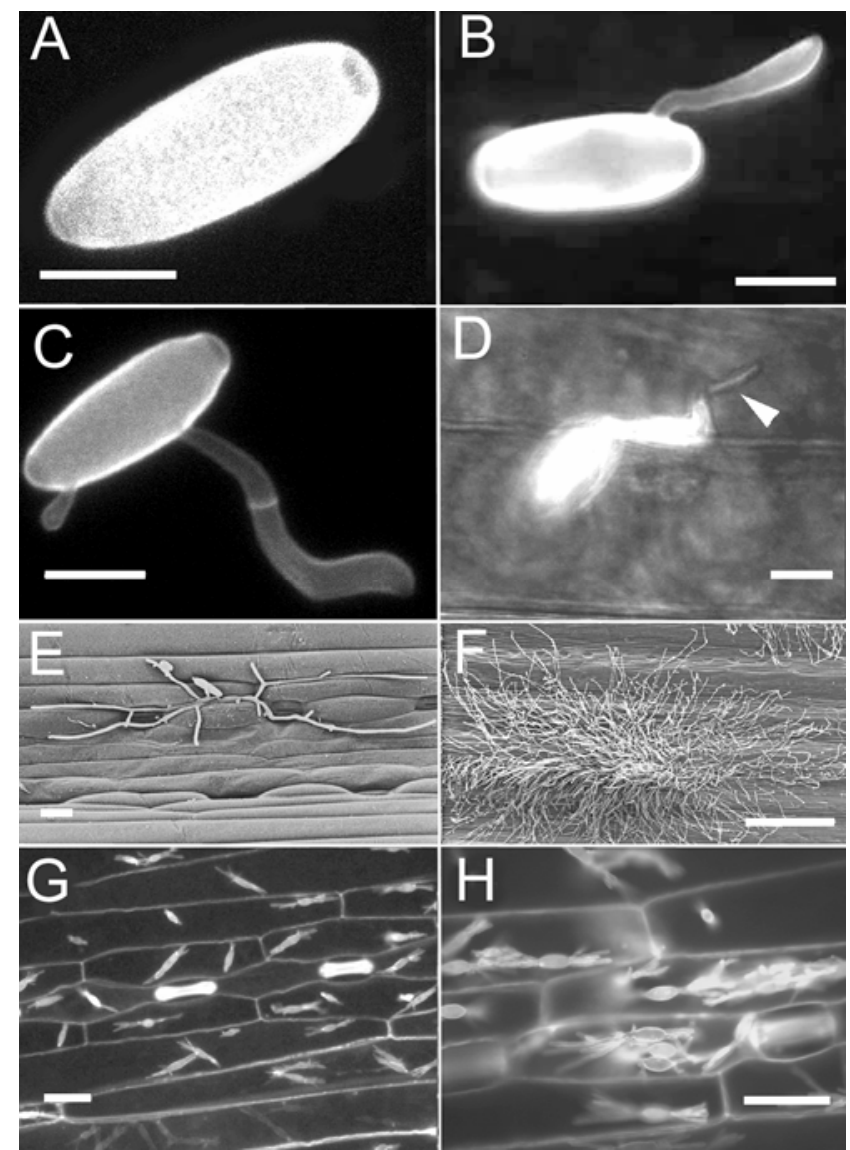

Fig. 1. The stages of Blumeria graminis development whose transcriptional profiles were probed with the microarrays. A, Ungerminated conidium. Bar $=10 \mu \mathrm{m}$. B, Germinated conidium $4 \mathrm{~h}$ postinoculation (hpi). The secondary germ tube is clearly visible on the right; the primary germ tube (arrow) is below the plane of focus. Bar $=10 \mu \mathrm{m}$. C, Germinated conidium $8 \mathrm{hpi}$. An appressorium is beginning to differentiate and is delimited from the secondary germ tube by a septum. Bar $=10 \mu \mathrm{m}$. D, $B$. graminis germling 15 hpi. A hypha (arrow) has penetrated the epidermal cell wall and will go on to develop a haustorium. Bar $=10 \mu \mathrm{m}$. E, Epiphytic mycelium 3 days postinfection (dpi). Hyphae bud off the secondary germ tube and proliferate on the barley leaf surface; secondary appressoria enable the fungus to penetrate barley epidermal cells. At this stage, there is no evident differentiation of conidiophores. Bar $=20 \mu \mathrm{m}$. F, Epiphytic mycelium 5 dpi. The colonies have expanded on the surface of the epidermis, and conidiophores have differentiated to produce abundant asexual conidia. Bar $=100 \mu \mathrm{m}$. G, Infected epidermis 3 dpi. Some of the epidermal cells beneath the colonies contain multidigitate haustoria. $\mathrm{Bar}=20$ $\mu \mathrm{m}$. H, Infected epidermis $5 \mathrm{dpi}$. The epidermal cells beneath the colonies can contain many haustoria. Bar $=20 \mu \mathrm{m}$. The images in A through D as well as $\mathrm{G}$ and $\mathrm{H}$ are optical micrographs of infected leaves and fungal structures labeled with wheat germ agglutinin-Alexa 488, observed by epifluorescence microscopy. $\mathrm{E}$ and $\mathrm{F}$ are scanning electron micrographs of the surface of infected leaves. different stages of asexual development in B. graminis: ungerminated conidia (Fig. 1A), harvested directly from heavily infected barley, and conidia germinated on barley leaves 4,8 , and $15 \mathrm{~h}$ postinoculation (hpi). Under the conditions used in this study, the majority of the germlings produced a primary and secondary germ tube (4 hpi; Fig. 1B), a differentiated appressorium (8 hpi; Fig. 1C), and an appressorium with evidence of penetration (15 hpi; Fig. 1D). In addition to this, we sampled the epiphytic mycelium $3 \mathrm{dpi}$, when there was little or no sporulation (Fig. 1E), and $5 \mathrm{dpi}$, when the colonies were sporulating abundantly (Fig. 1F). We also extracted RNA from infected barley epidermis 3 and $5 \mathrm{dpi}$, after removal of the epiphytic structures (mycelium and conidia); the latter two samples contained RNA from both infected epidermis cells and the $B$. graminis haustoria within them (Fig. $1 \mathrm{G}$ and $\mathrm{H}$ ). Three independent biological replicates were sampled for each stage. Labeled cDNA was synthesized from each independent sample and was used in separate hybridizations. A universal standard used as reference was assembled by combining equal amounts of RNA from all the developmental stages in the experiment. The reference cDNA was labeled with Cy5 and was cohybridized to the cDNA microarrays together with the Cy3-labeled sample probes. The data was expressed as a ratio between the intensity of fluorescence in the test sample and the universal reference.

A dye-swap experiment (mycelium vs. conidia) was conducted to validate the consistency of the labeling procedure. The $\log _{2}$-transformed data was inverted for one experiment, and the resulting scatter plot showed a linear line of best fit with the formula $y=0.98 x-0.027$. This demonstrated that the expression ratios of both experiments correspond to each other and confirms that the measured intensities for $\mathrm{Cy} 3$ and $\mathrm{Cy} 5$ are similar (not shown).

The complete set of expression data derived from these experiments is available at the COGEME website.

Validation of the microarray results by quantitative PCR.

We tested whether the relative expression values obtained from the microarray data could be verified independently, using quantitative PCR. Three target cDNAs were chosen for this purpose. These are homologous to histone $\mathrm{H} 3$, fructose1,6-bis phosphatase, and a plasma membrane $\mathrm{H}^{+}$-ATPase. From the microarray results (Fig. 2A), we observed that the abundance of histone H3 RNA was constant throughout development, relative to the universal standard. The fructose1,6-bis phosphatase RNA, on the other hand, was expressed at high levels in ungerminated conidia and in germlings 4,8 , and 15 hpi and levels dropped about 16-fold in the postpenetrative stages. The RNA encoding plasma membrane $\mathrm{H}^{+}-$ ATPase followed a completely different trend from fructose1,6-bis phosphatase; a significant, eightfold increase after germination continued up to $8 \mathrm{hpi}$ and then decreased in the 15-hpi stage as well as in the epiphytic mycelium. High levels were observed in the samples from the barley epidermis that contained B. graminis haustoria.

To validate the microarray expression data, we synthesized double-labeled TaqMan probes specific for the three cDNAs and measured the relative abundance of each RNA during the developmental time course. The results were plotted by expressing the levels of fructose-1,6-bis phosphatase and plasma membrane $\mathrm{H}^{+}$-ATPase RNA relative to those of histone $\mathrm{H} 3$ on the same semilogarithmic scale used for the microarray results (Fig. 2B). The absolute abundance of the RNA from both genes was generally lower than that of histone $\mathrm{H} 3$. The fructose-1,6-bis phosphatase transcripts were relatively abundant in ungerminated conidia and in the prepenetration stages; their level then dropped dramatically in the epiphytic mycelium (the 
slight increase in signal for the 5-day-old mycelium coincided with the onset of conidiation) and in the samples that contain haustoria. The $\mathrm{H}^{+}$-ATPase RNA was scarce in conidia, increased upon germination and formation of the appressorium, decreased again during formation of the penetration pegs and epiphytic hyphae, but was markedly higher in the infected epidermis.

\section{Global correlation.}

In an initial analysis of the data, we compared the overall expression levels of each cDNA on the microarray for all stages sampled. These results were plotted as a pair-wise comparison (Fig. 3) in which positive correlation is given in red and negative correlation in green. In the first instance, it is evident that the highest level of correlation was between samples
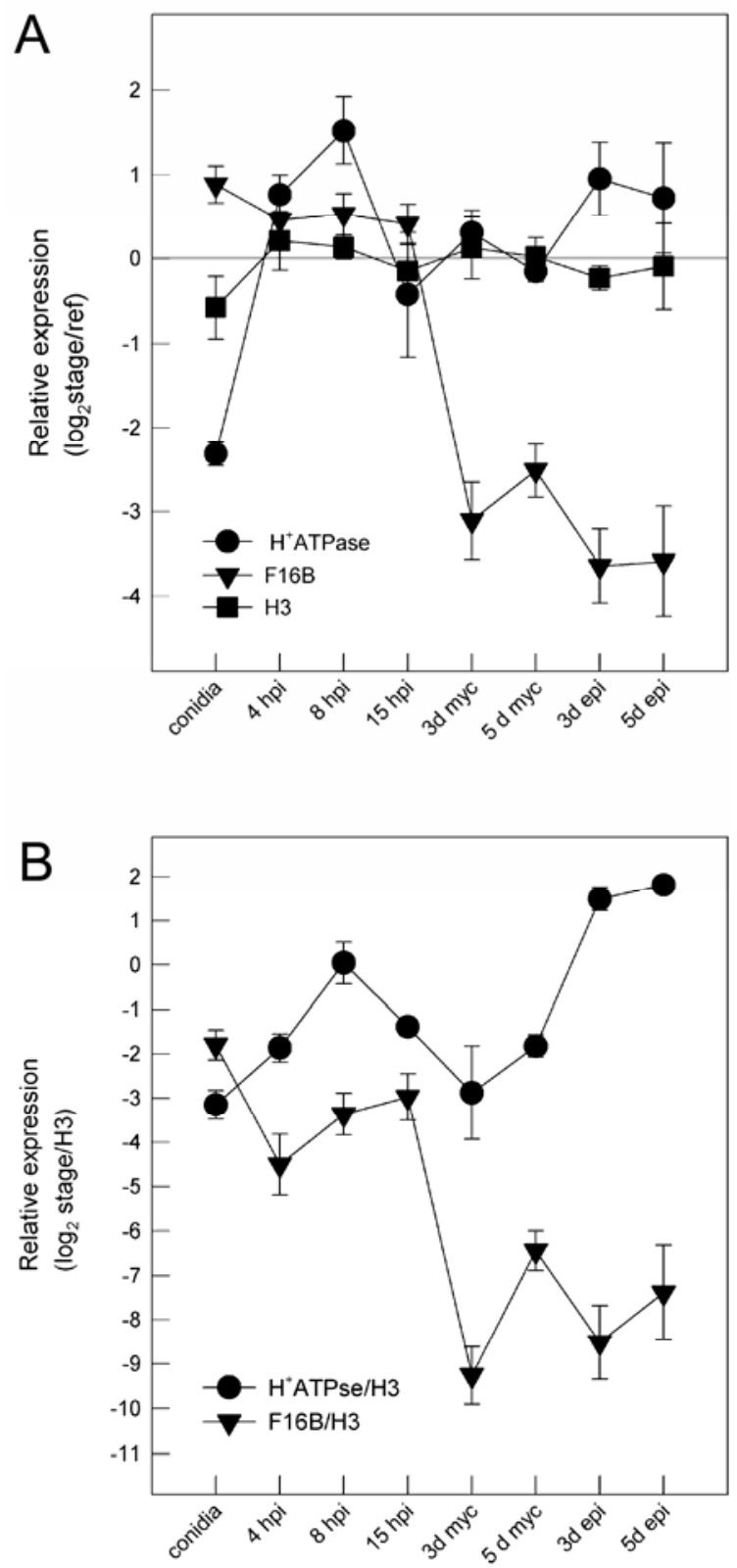

Fig. 2. Comparison between the analysis of RNA abundance, using microarrays and quantitative polymerase chain reaction (PCR). A, Microarray measure of the RNA levels of three genes $\left(\boldsymbol{\bullet}=\mathrm{H}^{+}\right.$-ATPase, $\boldsymbol{\nabla}=$ fructose1,6-bis phosphatase, and $\mathbf{\square}=$ histone $\mathrm{H} 3$ ) are expressed compared with the universal reference standard. B, Quantitative PCR measure of RNA levels of $\mathrm{H}^{+}$-ATPase (-) and fructose-1,6-bis phosphatase ( $\boldsymbol{\nabla}$ ) relative to histone H3 RNA. Mean and standard deviation of the $\log _{2}$ ratio values of the independent replicates for each stage are shown. obtained from the same developmental stage; only one of the samples from the epiphytic mycelium 3 dpi appeared to be an outlier. A second observation was the evident shift in the global pattern of gene expression from the prepenetration stages ( 0 to $15 \mathrm{hpi}$ ) to the postpenetration stages (epiphytic and endophytic mycelial structures).

A multiple $t$-test identified the genes expressed at levels that were significantly different when pre- and postpenetration stages were compared. These genes were sorted into functional categories as shown in Table 1 . The results indicate that the genes mostly responsible for the global shift were those devoted to protein biosynthesis. This category contains principally ribosomal proteins and some other genes related to translation. Other groups that showed prominent differences include car-

Table 1. Functional classification of genes that are up-regulated in pre- or postpenetration stages of Blumeria graminis development ${ }^{\mathrm{a}}$

\begin{tabular}{lcc}
\hline & \multicolumn{2}{c}{ Proportion of genes up-regulated } \\
\cline { 2 - 3 } Functional classes & Prepenetration & Postpenetration \\
\hline Protein biosynthesis & 2.0 & 19.5 \\
Nucleic acid metabolism & 2.9 & 5.4 \\
Amino acid metabolism & 2.0 & 3.6 \\
Protein modification & 4.3 & 3.4 \\
Carbohydrate metabolism & 5.4 & 2.7 \\
Transporter & 3.6 & 2.7 \\
Electron transport & 2.3 & 2.2 \\
Signal transduction & 2.9 & 1.2 \\
Stress-related & 0.7 & 1.5 \\
Lipid metabolism & 1.6 & 0.7 \\
Sterol metabolism & 0.0 & 0.7 \\
Cell wall & 1.1 & 0.0 \\
Oxidative stress & 0.5 & 0.0 \\
Virulence & 1.4 & 0.0 \\
Hypothetical protein & 10.6 & 7.1 \\
Unknown & 49.8 & 43.1 \\
Other & 8.4 & 5.8 \\
\hline
\end{tabular}

${ }^{a}$ The developmental stages were classified as either prepenetration (conidia, $4,8,15 \mathrm{hpi}$ ) or postpenetration ( 3 or 5 dpi myc, 3 or 5 dpi epi). A multiple $t$-test was applied to expression levels of the genes to identify those that are significantly up-regulated in either one or the other class, and these were ranked in order of significance. The top ranking genes in each class (prepenetration: 442; postpenetration: 411) were placed into the functional categories described above and the percentage of genes in each category is shown in this table.



Fig. 3. Overall correlation between the expression of each expressed sequence tag at the different stages of differentiation. Pairwise comparison between each developmental stage. Degree of correlation is indicated by the color: red is positive correlation, green is negative correlation. 
bohydrate metabolism, signal transduction, lipid metabolism, cell wall, oxidative stress and virulence (up-regulated prepenetration), and nucleic acid metabolism and sterol metabolism (up-regulated postpenetration).

We chose to show in some detail the expression of genes encoding ribosomal components and genes that are required for virulence in other plant-pathogenic fungi. There were $456 \mathrm{cDNAs}$ on the arrays that encode components of the ribosome, including genes encoding both ribosomal RNA and ribosomal proteins. The analysis of the expression of 50 ribosomal cDNAs chosen at random is displayed in Figure 4. There was a noticeable overall increase in the frequency of these RNAs in the epiphytic mycelium 3-dpi (and to a lesser extent the 5-dpi) samples compared with the rest of the developmental time course.

\section{Expression of genes associated with virulence.}

The global correlation analysis showed that a small but significant group of genes related to virulence were up-regulated in the prepenetration stages of development (Table 1). We tracked the expression pattern of a cap20 homolog during the development of B. graminis (Fig. 5). After germination, the RNA abundance of this gene increased, reached a peak $8 \mathrm{hpi}$, decreased again at $15 \mathrm{hpi}$, and settled to low basal levels thereafter. We used the profile-distance search function of the Expressionist software to identify a cluster of cDNAs whose expression profiles correlated with that of cap20 (Fig. 5). Tables 2 and 3 list all those genes whose expression show a coefficient of correlation greater than 0.8. In Table 2, we show the genes whose function was predicted by annotation based on homology with sequences in the databases. A striking feature of this table is the high incidence of ESTs that are homologous to pathogenicity genes (egh16, egh16H1, cPKA, and clap1). The second group of ESTs in Table 2 is composed of cDNAs that are homologous to genes associated with pathogenic development or with the establishment of infection but for which definite evidence based on mutant analysis has not been forthcoming (NADPH oxidase, serine protease, aspartic protease, and the MAP (mitogen-activated protein) kinase kinase $b k k l$ ). Other ESTs were identified by homology to genes of other fungi with no specified function but that are associated with a particular response, e.g., the stress response protein rds1p of Neurospora crassa.

In Table 3, we list cDNAs in the expression cluster whose function cannot be readily identified. In this group, there are

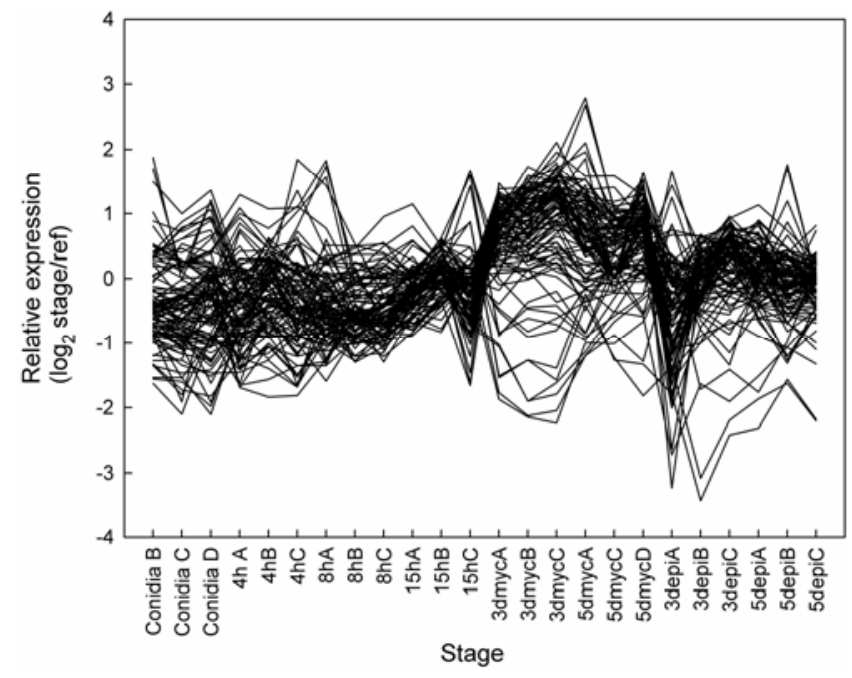

Fig. 4. RNA levels of 50 ribosomal RNA and ribosomal protein genes chosen at random from the microarray analysis. The expression values relative to the universal standard are shown for all the stages. Individual replicates for each stage are shown separately. two ESTs homologous to "hypothetical proteins" identified in other fungi (some of them plant pathogens) and 21 ESTs that are "orphan," i.e., encoding hypothetical proteins of no known homology to any current entries in the databases.

\section{DISCUSSION}

In this study, we have used cDNA microarrays for largescale analysis of gene expression during development of the obligate biotrophic pathogen $B$. graminis. The array we have constructed contained 2,027 unigenes that are present in cDNA libraries obtained from conidia, germinated conidia (Thomas et al. 2001), and epiphytic mycelium isolated immediately before the onset of massive conidiation. The frequency at which individual cDNAs are present in the libraries reflects the relative abundance of the RNA transcripts at the stage used to make the libraries themselves. This fact was confirmed by the observation that, on the whole, target cDNAs were labeled more intensely when probed with the cDNAs isolated from the same stage (data not shown). By using three libraries from diverse stages in $B$. graminis development, we hoped to be able to probe a representative sample of the most abundant genes expressed throughout the asexual life cycle.

We estimate that this array represented one fifth to one sixth of the total gene complement of this fungus, based on the available data on genome statistics in related ascomycete fungi; thus, the current estimates are Aspergillus nidulans $(9,457)$, Fusarium graminearum $(11,640), M$. grisea $(11,108)$ and $N$. crassa (10,082 genes). Confirmation of this estimate requires the definition of the precise number of $B$. graminis genes from a complete genome sequence. The microarrays enabled us to follow the expression of these genes throughout the whole of the cycle of asexual development and infection on barley, germination of

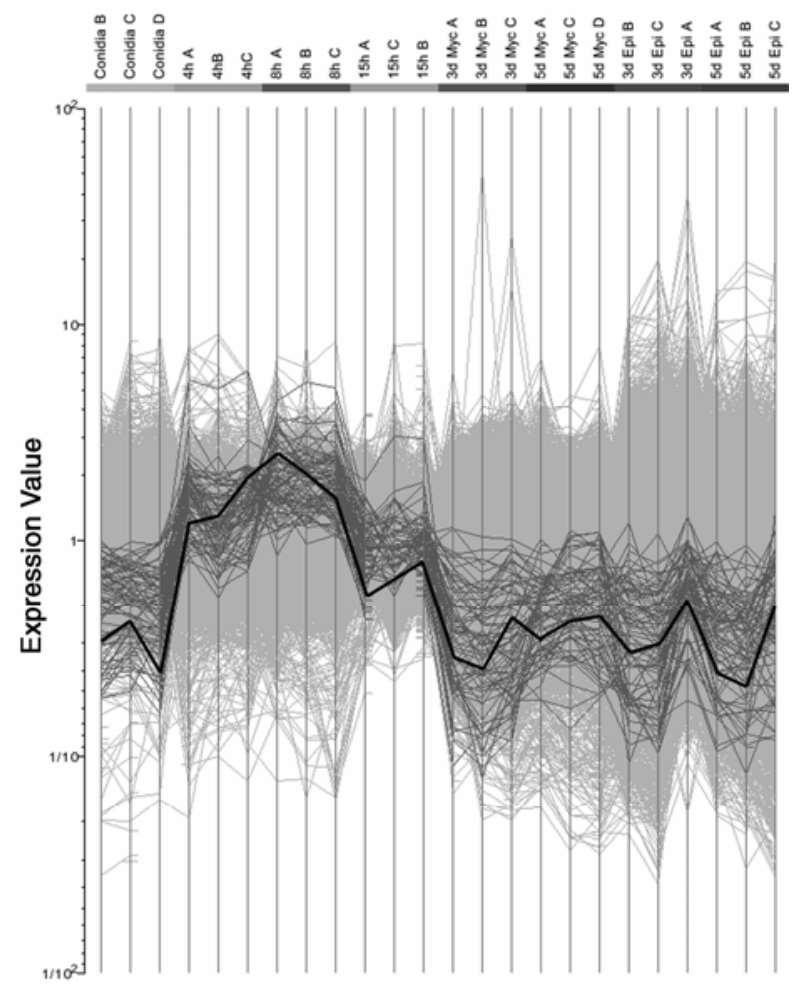

Fig. 5. Expression profiles of an expressed sequence tag (EST) homologous to cap20 (black line) superimposed over profiles of the ESTs whose expressions correlate to the cap20 homologs (dark gray lines) and over the totality of the expression profiles (light gray lines). Individual replicates for each stage are shown separately. 
the conidia, production of primary and secondary germ tubes, formation of appressoria, penetration of the epidermal cells, proliferation of hyphae on the leaf surface, up to the development of conidiophores and conidiation. We were also able to probe gene expression inside the infected epidermis. The samples from infected epidermis included RNA from barley epidermal cells as well as from the fungal haustoria contained within them. Hybridization analysis of the RNAs extracted from uninfected epidermis indicated that the signals derived from the plant tissues alone were significantly lower than those from mixed plantfungus samples (data not shown). Although we cannot exclude that some of the hybridization signal derived from the plant and was caused by cross-hybridization with the fungal cDNAs, most of the signal resulted from the hybridization with homologous fungal sequences. This was supported by the validation studies using quantitative PCR (discussed below).

Preliminary hybridizations with probes from conidia and epiphytic mycelium ( $3 \mathrm{dpi}$ ) indicated that not all targets on the array provided a signal and, therefore, had to be discarded from the analysis. This is a serious drawback because, in experiments where many different conditions are compared, only a fraction of the targets yield data that can be used. In order to avoid this, we used a universal reference sample made up of a pool of cDNAs, used to probe each stage in a similar way to that described by Sterrenburg and associates (2002).

In order to validate the results of the microarrays, we compared the transcriptional profiles obtained from the arrays with quantitative PCR measurements of the RNA abundance of a histone (H3), fructose-1,6-bis phosphatase, and of $\mathrm{H}^{+}$-ATPase. We selected the histone as an RNA whose abundance did not vary extensively during development. The histone was then used as the reference standard for normalization of the quantitative PCR data. The fructose-1,6-bis phosphatase and the $\mathrm{H}^{+}$ATPase were chosen because their microarray expression profiles differed significantly from each other. Fructose-1,6-bis phosphatase was most highly expressed in the early infection

Table 2. Cluster of genes whose expression correlates (coefficient of correlation $>0.8$ ) with a CAP20 homolog

\begin{tabular}{|c|c|c|c|c|c|}
\hline $\begin{array}{l}\text { Library } \\
\text { reference }^{\mathrm{a}}\end{array}$ & Homology (accession) ${ }^{b}$ & E value ${ }^{c}$ & $\begin{array}{c}\text { Correlation } \\
\text { coefficient (average) }^{\mathrm{d}}\end{array}$ & $\begin{array}{l}\text { Number of } \\
\text { clones in cluster }\end{array}$ & $\begin{array}{c}\text { Role in } \\
\text { pathogenicity }\end{array}$ \\
\hline $\mathrm{C} 00750$ & Blumeria graminis CAP20-like protein mRNA $(\mathrm{AF} 283105)^{1}$ & 0 & 0.988 & 2 & Yes \\
\hline C00508 & B. graminis gEgh16 gene (L40637) & 0 & 0.90 & 2 & Yes \\
\hline $\mathrm{C} 00727$ & $\begin{array}{l}\text { Neurospora crassa mitochondrial import receptor subunit } \\
\text { TOM40 (P24391) }\end{array}$ & $1.00 \mathrm{E}-23$ & 0.897 & 2 & $\mathrm{~N} / \mathrm{I}$ \\
\hline $\mathrm{C} 00059$ & B. graminis CPKA gene $(\mathrm{AJ} 243654)^{1}$ & $7.00 \mathrm{E}-79$ & 0.892 & 1 & Yes \\
\hline C00566 & $\begin{array}{l}\text { Aspergillus fumigatus } 1,3-\beta \text {-glucanosyltransferase, GEL1 } \\
(\mathrm{O} 74687)^{2}\end{array}$ & $3.00 \mathrm{E}-21$ & 0.891 & 1 & $\mathrm{~N} / \mathrm{I}$ \\
\hline C01205 & $\begin{array}{l}\text { B. graminis Egh16H1, homologous to M. grisea GAS } 2 \\
\text { (AAK25794) }^{1}\end{array}$ & 0 & 0.887 & 9 & Yes \\
\hline C00688 & $\begin{array}{l}\text { Macaca fascicularis palmitoyl-protein thioesterase } \\
(\mathrm{Q} 8 \mathrm{HXW6})^{3}\end{array}$ & $3.00 \mathrm{E}-16$ & 0.884 & 2 & $\mathrm{~N} / \mathrm{I}$ \\
\hline $\mathrm{C} 00522$ & $\begin{array}{l}\text { Dictyostelium discoideum alpha-actinin, nonmuscular } \\
\text { (F-actin cross linking protein) }(\mathrm{P} 05095)^{2}\end{array}$ & $1.00 \mathrm{E}-08$ & 0.876 & 2 & $\mathrm{~N} / \mathrm{I}$ \\
\hline D01047 & Podospora anserina NADPH oxidase (AAQ74977) ${ }^{1}$ & $3.00 \mathrm{E}-66$ & 0.868 & 1 & $?$ \\
\hline D01283 & Colletotrichum lindemuthianum CLAP1 (Q8J286) ${ }^{3}$ & $5.00 \mathrm{E}-19$ & 0.865 & 2 & Yes \\
\hline C01716 & $\begin{array}{l}\text { N. crassa protein related to stress response protein rds1p } \\
(\mathrm{Q} 8 \mathrm{X} 0 \mathrm{R} 9)^{3}\end{array}$ & $3.00 \mathrm{E}-12$ & 0.855 & 5 & $\mathrm{~N} / \mathrm{I}$ \\
\hline C01493 & $\begin{array}{l}\text { Saccharomyces cerevisiae repressible alkaline phosphatase } \\
\text { precursor }(\mathrm{P} 11491)^{2}\end{array}$ & $1.00 \mathrm{E}-44$ & 0.850 & 2 & $\mathrm{~N} / \mathrm{I}$ \\
\hline $\mathrm{C} 00323$ & B. graminis extracellular chitinase (Chi1) (AY039007) ${ }^{1}$ & 0 & 0.848 & 4 & $\mathrm{~N} / \mathrm{I}$ \\
\hline $\mathrm{C} 00840$ & $\begin{array}{l}\text { N. crassa protein related to translation initiation factor 4E } \\
(\mathrm{Q} 9 \mathrm{C} 2 \mathrm{M} 5)^{3}\end{array}$ & $1.00 \mathrm{E}-22$ & 0.848 & 5 & $\mathrm{~N} / \mathrm{I}$ \\
\hline C00741 & $\begin{array}{l}\text { Aspergillus niger probable signal recognition particle subunit } \\
\text { SRP54 (Q00179) }\end{array}$ & $5.00 \mathrm{E}-10$ & 0.842 & 2 & N/I \\
\hline $\mathrm{C} 00018$ & B. graminis $g E g h 7$ gene $(\mathrm{L} 40638)^{1}$ & 0 & 0.836 & 9 & $\mathrm{~N} / \mathrm{I}$ \\
\hline D00869 & $\begin{array}{l}\text { N. crassa probable U6 snRNA-associated SM-like protein } \\
\text { LSM5 (Q96UB4) }\end{array}$ & $2.00 \mathrm{E}-11$ & 0.836 & 1 & $\mathrm{~N} / \mathrm{I}$ \\
\hline C00933 & $\begin{array}{l}\text { Colletotrichum gloeosporioides hard surface-induced protein } \\
3 \text { (Q9UUS8) }\end{array}$ & 4.00E-09 & 0.829 & 2 & $?$ \\
\hline D01065 & $\begin{array}{l}\text { Schizosaccharomyces pombe probable vesicular protein } \\
\text { transport protein }(\mathrm{O} 74786)^{3}\end{array}$ & $6.00 \mathrm{E}-13$ & 0.826 & 3 & $\mathrm{~N} / \mathrm{I}$ \\
\hline D00457 & B. cinerea aspartic proteinase precursor (AAR87747) ${ }^{1}$ & $4.00 \mathrm{E}-17$ & 0.825 & 2 & ? \\
\hline C01735 & N. crassa serine hydroxymethyltransferase $(\mathrm{P} 34898)^{2}$ & $2.00 \mathrm{E}-10$ & 0.824 & 1 & $\mathrm{~N} / \mathrm{I}$ \\
\hline C01244 & $\begin{array}{l}\text { N. crassa protein related to the putative transporter } \mathrm{PHO} 87 \\
(\mathrm{Q} 8 \mathrm{WZZ1})^{3}\end{array}$ & $2.00 \mathrm{E}-18$ & 0.822 & 2 & $\mathrm{~N} / \mathrm{I}$ \\
\hline C01246 & B. graminis glucose transporter $($ gltrn 1$)(\mathrm{AF} 376000)^{1}$ & 0 & 0.816 & 5 & $\mathrm{~N} / \mathrm{I}$ \\
\hline $\mathrm{C} 00172$ & Pyrenopeziza brassicae serine protease $1(\mathrm{Q} 8 \mathrm{WZP} 0)^{3}$ & $8.00 \mathrm{E}-51$ & 0.815 & 6 & $?$ \\
\hline C00732 & Botrytis cinerea cytosolic cyclophilin 1 (AAQ16573) ${ }^{1}$ & $2.00 \mathrm{E}-42$ & 0.811 & 2 & $\mathrm{~N} / \mathrm{I}$ \\
\hline D00264 & $\begin{array}{l}\text { B. graminis mitogen-activated protein kinase kinase } b k k 1 \\
(\mathrm{AJ} 304831)^{1}\end{array}$ & 0 & 0.808 & 1 & $?$ \\
\hline C00681 & B. graminis repetitive element DNA $(\mathrm{Z} 21962)^{1}$ & $8.00 \mathrm{E}-22$ & 0.804 & 1 & N/I \\
\hline C01357 & Humicola grisea glucoamylase $(\mathrm{Q} 12623)^{3}$ & $6.00 \mathrm{E}-43$ & 0.803 & 2 & $\mathrm{~N} / \mathrm{I}$ \\
\hline
\end{tabular}

a Array identifier; code number assigned to the expressed sequence tag (EST) clone with the highest coefficient of correlation to C00750 (cap20 homolog).

${ }^{\mathrm{b}}$ Description of the homolog of known or putative function with the highest $\mathrm{E}$ value. The accession numbers refer to the following databases: ${ }^{1} \mathrm{GenBank}$ at NCBI, ${ }^{2}$ SwissProt, and ${ }^{3}$ TrEMBL.

${ }^{\mathrm{c}} \mathrm{E}$ value of the homolog.

${ }^{\mathrm{d}}$ Average coefficient of correlation of the expression profile of the clones in this cluster.

e Number of homologous EST clones in the cluster.

${ }^{\mathrm{f}}$ Yes = ESTs that are homologs of genes whose function in plant pathogenicity has been demonstrated by mutational analysis, ?= ESTs that are homologs of genes whose function has been proposed to be involved in pathogenicity but for which experimental proof is lacking, and N/I = not investigated. 
stages and decreased significantly after penetration and during proliferation. This pattern of expression is consistent with the relatively high levels of fructose-1,6-bis phosphatase in the early stages of $B$. graminis as reported by Thomas and coworkers (2002). There was a striking decrease after penetration of the plant. This enzyme is involved in gluconeogenesis, and the trends in expression suggest that gluconeogenesis is more important in the early stages when storage compounds from the conidia are used for growth, whereas in the later phases sugars are taken up from the host via the haustoria. A full interpretation of the biological significance of these changes will have to await an analysis of the transcript profiles of genes involved in primary metabolism (M. Both, M. Csukai, and P. D. Spanu unpublished data).

In contrast to this, $\mathrm{H}^{+}$-ATPase RNA increased during development of the appressorium and did so most conspicuously in the infected epidermal cells, where haustoria are formed. Although, to our knowledge, there are no studies on the expression of one or more $\mathrm{H}^{+}$-ATPase genes in the haustoria of $B$. graminis, it is generally accepted that a plasma membrane $\mathrm{H}^{+}$ATPase generates an electrochemical potential that enables the haustorium to take up nutrients from the plant cell (Green et al. 2002; Schulze-Lefert and Panstruga 2003). In the rust fungus Uromyces viciae-fabae $\mathrm{H}^{+}$-ATPase is encoded by the pmal gene (Struck et al. 1998). pmal RNA increases after germination; our microarray data show that in these stages of development the expression of the $\mathrm{H}^{+}$-ATPase in B. graminis is similar to pmal. It is not clear what the function of an increased $\mathrm{H}^{+}$ATPase activity on the plasma membrane of germlings 4 and 8 hpi might be, as at this stage the fungus is not thought to be absorbing nutrients from the environment. In the haustoria of
U. viciae-fabae, the pmal RNA appears lower than in earlier stages, in spite of the fact that the enzyme activity is significantly greater than in conidia; this suggests posttranscriptional regulation of expression of pmal (Struck, et al. 1998). It remains to be seen whether the $B$. graminis $\mathrm{H}^{+}$-ATPase is regulated in a similar manner.

On the whole, these results are internally consistent because the relative trends obtained using the two different techniques are comparable, including the samples of mixed epidermis and haustorial RNA. Moreover, the microarray data obtained for these two genes are in agreement with data found independently and published elsewhere. Thus, we are confident that this validates the use of our microarray data as a reliable reflection of the levels of RNA abundance during development of $B$. graminis on barley.

The global comparison of the expression data for all the cDNAs throughout development revealed that overall gene expression changed significantly between the pre- and postpenetration stages. This probably reflected a major switch in metabolism and cellular processes as the fungus moved from using its endogenous reserves to grow and develop penetrative structures to an assimilatory phase in which nutrients are taken up from the host, fungal hyphae proliferate, and abundant conidia are formed on the surface of the plant. A profile display that shows a random selection of cDNAs encoding elements of the translation machinery, such as the ribosomal RNAs and proteins, highlighted the overall relative increase of these genes after penetration of the host. This increase was not of a great magnitude but, nevertheless, was significant because of the large number of cDNAs following this trend. This coincides with the proliferation of hyphae on the surface of the leaf and the onset of conidi-

Table 3. Cluster of "orphan genes" whose expression correlates (coefficient of correlation $>0.8$ ) with a CAP20 homolog

\begin{tabular}{|c|c|c|c|c|}
\hline $\begin{array}{l}\text { Library } \\
\text { reference }^{\text {a }}\end{array}$ & Homology (accession) ${ }^{b}$ & E value ${ }^{c}$ & $\begin{array}{c}\text { Correlation } \\
\text { coefficient (average) }\end{array}$ & $\begin{array}{l}\text { Number of clones } \\
\text { in cluster }\end{array}$ \\
\hline D00283 & Unknown & & 0.879 & 2 \\
\hline \multirow{3}{*}{$\mathrm{C} 01112$} & Botrytis cinerea hypothetical protein (AL113946) ${ }^{1}$ & $2.00 \mathrm{E}-25$ & 0.861 & 1 \\
\hline & Magnaporthe grisea hypothetical protein (MG03609.4) ${ }^{2}$ & $1.00 \mathrm{E}-12$ & & \\
\hline & Fusarium graminearum hypothetical protein $(\mathrm{FG} 00908.1)^{3}$ & $2.00 \mathrm{E}-12$ & & \\
\hline $\mathrm{C} 00354$ & Unknown & & 0.857 & 2 \\
\hline \multirow[t]{3}{*}{ D00146 } & Neurospora crassa DNA linkage group II BAC clone B17B1 (BX284750)4 & $1.00 \mathrm{E}-64$ & 0.856 & 3 \\
\hline & F. graminearum hypothetical protein $(\mathrm{FG} 01453.1)^{3}$ & $4.00 \mathrm{E}-60$ & & \\
\hline & M. grisea hypothetical protein (MG01604.4)2 & $6.00 \mathrm{E}-16$ & & \\
\hline $\mathrm{C} 01470$ & Unknown & & 0.855 & 2 \\
\hline D00787 & Unknown & & 0.852 & 1 \\
\hline D00438 & Unknown & & 0.849 & 1 \\
\hline $\mathrm{C} 00623$ & Unknown & & 0.842 & 2 \\
\hline D00124 & Unknown & & 0.842 & 1 \\
\hline $\mathrm{C} 00623$ & Unknown & & 0.842 & 2 \\
\hline C01409 & Unknown & & 0.836 & 2 \\
\hline $\mathrm{C} 01163$ & Unknown & & 0.83 & 1 \\
\hline D00516 & Unknown & & 0.83 & 1 \\
\hline D01366 & Unknown & & 0.826 & 2 \\
\hline C01148 & Unknown & & 0.821 & 1 \\
\hline D00015 & Unknown & & 0.817 & 1 \\
\hline C01692 & Unknown & & 0.817 & 2 \\
\hline D00135 & Unknown & & 0.815 & 2 \\
\hline $\mathrm{C} 00734$ & Unknown & & 0.812 & 1 \\
\hline C00838 & Unknown & & 0.81 & 2 \\
\hline C00122 & Unknown & & 0.807 & 1 \\
\hline D00269 & Unknown & & 0.807 & 2 \\
\hline D00011 & Unknown & & 0.801 & 1 \\
\hline
\end{tabular}

a Array identifier. Code number assigned to the expressed sequence tag (EST) clone with the highest coefficient of correlation to C00750 (cap20 homolog).

$\mathrm{b}$ Description of the orphan. Hypothetical proteins are sequences identified as potentially encoding proteins. Several hits for different organisms are shown.

The identity of the database or search programs used are: ${ }^{1} \mathrm{NCBI}$, tBLASTx, ${ }^{2}$ BLASTx Magnaporthe grisea database at the Broad Institute, ${ }^{3}$ BLASTx

Fusarium graminearum database at the Broad Institute , and ${ }^{4}$ tBLASTx EMBL fungi database.

${ }^{c} \mathrm{E}$ value of the homolog with the highest coefficient of correlation to C00750 (cap20 homolog).

d Average coefficient of correlation of the expression profile of the clones in this cluster.

e Number of homologous EST-arrayed clones in the cluster. 
ation. Both these processes are likely to require active protein synthesis to supply the protein of the newly produced cellular structures. In fact, in the filamentous fungus $A$. nidulans, the transcripts encoding ribosomal proteins increase in association with enhancement of the growth rate (Sims et al. 2004).

We observed that a number of genes related to virulence appeared to be induced in the early prepenetration stages of development. The microarray contained various cDNAs that are homologs of genes known to be required for full pathogenicity in other plant-pathogenic fungi. For example, cap20 is a Colletotrichum gloeosporioides gene that accumulates during formation of appressoria and whose removal determines a marked reduction in virulence (Hwang et al. 1995). The expression profile of the Blumeria cap20 homolog was similar to that described in Colletotrichum gloeosporioides (Hwang et al. 1995), in which both RNA and CAP20 protein accumulate during formation of the appressoria. We used expression cluster analysis (Profile Distance Search, Expressionist) to identify cDNAs whose expression profile correlated to that of cap20. Here, we list the genes whose coefficient of correlation was higher than an arbitrary value of 0.8 . It is evident that this cluster contained a very high proportion of genes that have either been demonstrated to be required for pathogenicity and full virulence in other plant pathogens or that may be associated with pathogenicity and virulence even if direct proof has not been forthcoming. Thus eghl6 and egh16H1 are homologs of the gas $1 /$ mas 3 and gas $2 /$ mas 1 genes described in Magnaporthe grisea as contributing to pathogenicity in this fungus (Xue et al. 2002). Like gasl and gas 2, the eghl6 and egh16H1 gene are expressed in germinating conidia and during primary infection (Grell et al. 2003), which is what we observed in the developmental time course described here. In $M$. grisea, cPKA is required for pathogenicity (Mitchell and Dean 1995; Xu et al. 1997) and the cPKA of B. graminis can functionally complement the $M$. grisea cPKA (Bindslev et al. 2001). clapl is a gene that is required for pathogenicity in Colletotrichum lindemuthianum (Parisot et al. 2002); clapl encodes a copper transporter, and in Colletotrichum lindemuthianum, it is essential for the formation of normal appressoria.

NADPH oxidases are instrumental in the generation of extracellular reactive oxygen (Lara-Ortiz et al. 2003), and there is evidence that this process is important for virulence in some pathogenic fungi, such as Botrytis cinerea (Rolke et al. 2004). Although Botrytis cinerea is a necrotrophic pathogen that infects plants in an entirely different manner to $B$. graminis, it is intriguing that the expression of $B$. graminis NADPH oxidase correlates so closely with other ESTs related to pathogenicity. Proteases might be involved in pathogenicity in other plant-pathogenic fungi, for example, as agents of cell wall depolymerization. In many cases, the genes are present as families, and functional redundancy might account for the failure of single gene knockout mutants to affect the phenotype (Batish et al. 2003; Bindschedler et al. 2003; Keniry et al. 2002; Murphy and Walton 1996). bkkl is homologous to the $m k k l$ gene of $M$. grisea that is considered to be the upstream regulator of PMK1, a kinase involved in pathogenicity (Xu 2000; Xu and Hamer 1996). PMK1 and its homologs in Cochliobolus heterostrophus (CHK1) and Colletotrichum lagenarium (CMK1) are all required for the formation of functional appressoria and as a consequence are needed for full pathogenicity. Thus, it is possible that $B$. graminis MAP kinase kinase $b k k 1$ is also involved in pathogenicity as the upstream regulator of the signal transduction kinase MPK1, the B. graminis homolog of PMK1 (Zhang and Gurr 2001).

The high incidence of genes in this cluster that are directly or indirectly linked to pathogenicity leads us to speculate that at least some of the other ESTs in the cluster also encode genes that contribute to virulence. Some of these genes have an anno- tation that identifies probable enzymatic or cellular functions. Chitinase Chil could contribute to cell wall formation and remodeling, as discussed by Thomas and associates (2002); the signal recognition particle subunit SRP54 and the putative vesicular transport protein are likely to be involved in protein secretion. We propose that it might be fruitful to investigate the function of these proteins by analysis of the phenotypes of the respective null or disrupted mutants in plant pathogens such as Botrytis cinerea and M. grisea.

The validity of defining gene function by a "guilt-by-association" approach has been discussed (Quackenbush 2003). Its principal limitation is that it risks confusing correlation with causality - a common pitfall in the interpretation of many experiments. In spite of this, the use of guilt-by-association does provide a platform for the proposal of hypotheses on gene function. This is particularly so in the case of obligate biotrophic pathogens, as is B. graminis, for which a direct mutational approach to the study of pathogenesis is not currently feasible. The availability of large-scale, reliable microarray data that produce a transcriptional profile of development and infection can lead to the identification of candidate pathogenicity genes. These may then be tested in more amenable model systems, such as the rice blast fungus $M$. grisea.

In this study, we have focused on those genes that are involved in virulence and pathogenicity because of their upregulation during development of the appressoria and that are therefore likely to be necessary either for appressorial formation (e.g., clap1) or for appressorial function (e.g., cap20). In the future, the discovery of genes that are required for the later stages of infection, i.e., after penetration, might also enable us to carry out similar studies for additional and novel identification of $B$. graminis genes required for growth and proliferation inside plant tissues.

\section{MATERIALS AND METHODS}

\section{Growth conditions of plants and fungi.}

The barley (cv. Golden Promise) was grown at $17^{\circ} \mathrm{C}$ and $60 \%$ relative humidity with $16 \mathrm{~h}$ of light and $8 \mathrm{~h}$ of dark for 7 to 14 days, and then was infected by dusting with $B$. graminis conidia (race IM82 [Chaure et al. 2000]). To ensure a homogeneous and consistently high germination rate, old conidia were shaken off the plants used to obtain the inoculum $24 \mathrm{~h}$ before infection. The inoculated plants were maintained in a greenhouse under supplemented light conditions (16-h light period) and a minimum temperature of $15^{\circ} \mathrm{C}$.

\section{Light microscopy.}

Infected leaves were incubated in $70 \%$ methanol overnight and then in chloral hydrate $(2 \mathrm{~g} / \mathrm{ml})$ for at least $8 \mathrm{~h}$. The leaves were then washed three times for $20 \mathrm{~min}$ in phosphate buffer saline (Karpovich-Tate et al. 1998), until the chloral hydrate was removed. The fungal structures were labeled with $5 \mu \mathrm{g}$ of wheat germ agglutinin per ml, coupled with Alexa-488 (Molecular Probes, Leiden, The Netherlands), and observed under an epifluorescence microscope (FITC filter).

\section{Scanning electron microscopy.}

Microscopy of the epiphytic mycelium 3 and 5 dpi was carried out on samples fixed in buffered glutaraldehye/formaldehyde, dehydrated in acetone, critical-point dried in $\mathrm{CO}_{2}$, mounted on a tub, and sputter-coated with gold. The samples were examined on a Philips 501(B) scanning electron microscope.

\section{Library construction.}

The mycelial cDNA library was produced from RNA extracted from 3-dpi epiphytic mycelium. The cDNA was synthe- 
sized using a SMART cDNA library construction kit as directed by the manufacturers (Clontech, Palo Alto, CA, U.S.A.). The inserts were then cloned into the SfiI restriction site of the TriplEx2 (Clontech), using the Gigapack III Gold kit (Stratagene, La Jolla, CA, U.S.A.). For sequencing, $\lambda$ TriplEx 2 was converted to the vector pTriplEx2 by cre/loxP-mediated excision in Escherichia coli BM25.8, as described by the supplier (Clontech). The Carlsberg library clones were obtained from the COGEME collection at Exeter University.

\section{Construction of Blumeria microarrays.}

Bacterial clones or plasmids were PCR-amplified using 5' amino $\left(\mathrm{C}_{12}\right)$-modified primers; the quality of all the amplified inserts was checked on $1 \%$ agarose gels. The DNA was precipitated with ethanol and sodium acetate using standard procedures (Sambrook et al. 1987) and was eluted in Genpak spotting buffer (Genetix, Hampshire, U.K.), resulting in a final concentration of 0.5 to $1 \mu \mathrm{g} / \mu \mathrm{l}$. The DNA was spotted on aminosilanecoated glass slides with the Omnigrid microarray spotter (GeneMachines, San Carlos, CA, U.S.A.). To cross-link the DNA, the slides were incubated at $60^{\circ} \mathrm{C}$ for $3 \mathrm{~h}$ and then at $100^{\circ} \mathrm{C}$ for $10 \mathrm{~min}$.

\section{RNA extraction, probe preparation, and microarray hybridization.}

Total RNA was extracted from conidia collected directly from the infected plant with a vacuum device. $B$. graminis germlings and epiphytic mycelia were isolated by dipping the infected leaf in 5\% cellulose acetate (dissolved in acetone), letting the acetone evaporate, and stripping the cellulose acetate film off the leaves. Total RNA was isolated from germlings and epiphytic mycelia using guanidine isothiocyanate (Chomczynsky and Sacchi 1987). The total RNA isolated from conidia was further purified by filter dialysis over diethylpyrocarbonate-treated water to remove substances that interfered with subsequent enzymatic reactions.

The infected epidermis containing haustoria was collected after first removing all epiphytic structures (hyphae and conidia), using cellulose acetate as described above. The RNA was then extracted using RNeasy extraction kits (Qiagen, Crawley, U.K.).

Total RNA was reverse-transcribed using a primer with oligo $\mathrm{d}(\mathrm{T})-\mathrm{T} 7$ promoter sequence, and the second strand was synthesized using reverse transcriptase (Superscript II, Invitrogen, San Diego, CA, U.S.A.). The double-stranded cDNA was amplified with the MEGAscript T7 RNA synthesis kit (Ambion, Austin, TX, U.S.A.). The resulting complementary mRNA was used for random-primed cDNA synthesis and direct label incorporation of Cy3-dUTP or Cy5-dUTP fluorescent nucleotide analogs (Amersham, Little Chalfont, U.K.) for the test probes or the reference sample, respectively. The probes were hybridized to the microarrays as described (Dimopoulos et al. 2002).

\section{Microarray data analysis.}

The hybridized slides were scanned with a Genepix 4000b scanner (AXON Instruments, Foster City, CA, U.S.A.) and software. When acquiring an image, the laser intensity of the two channels (635 and $532 \mathrm{~nm}$ ) was adjusted until the histograms of the two channels overlapped. The Genepix scanner output files were normalized with Expressionist Refiner (Genedata, Basel, Switzerland) by subsequently applying background correction, locally weighted linear regression correction, and unsupervised masking. An assessment of experiment quality was performed before and after the normalization steps. Distortion (deviation of the point cloud from the diagonal in the logplot scatter plot) and imbalance (systematic offset of the data cloud from main diagonal) were greatly improved for most experiments after normalization (data not shown). Contrast (estimate of overall strength of the signal on the array) and defective area (percentage of potentially defective area) cannot be improved with corrections but were of high standard for all experiments. The overall classification of the experiments rated 'good' or 'medium' for all experiments after normalization.

\section{TaqMan real-time PCR.}

TaqMan PCR reactions were performed in $25-\mu \mathrm{l}$ volumes containing $12.5 \mu \mathrm{l}$ of qPCR Mastermix Plus solution, consisting of thermostable polymerase, buffers, and reference dye (Eurogentec, Romsey, U.K.), $100 \mathrm{nM}$ forward and reverse primers, $300 \mathrm{nM}$ double-labeled oligonucleotide probe, and $5 \mu \mathrm{l}$ cDNA template. Oligonucleotide probes were labeled with FAM and ELLE dyes at the 5' and $3^{\prime}$ ends, respectively. Sequences of TaqMan primers and probes (Eurogentec, Romsey, U.K.) were: Histone H3 (forward primer, CGACTTGCGGTT CCAGTCA; reverse primer, ACACAAATTGGTATCCTCGA AGAGT; probe, TCCACCGACTCTTGAAGGGCACCAAT); Fructose-1,6,-bis phosphatase (forward primer, GAAAGTGC GCTGTGCTTGTTT; reverse primer, GGATCACAAGCTACC GCATACC; probe, AGACGCTATATTTTTTCCCGAACACC CTGGT); $\mathrm{H}^{+}$-ATPase (forward primer, TTCTGTCGTCCTGG GTATACTTTTG; reverse primer, TGTCGATCATTCCTCCAT TAGGTA; probe, ATTGGTACTTGGATTCTCAGAGGATCC CTCTTC). The PCR-amplification cycle conditions were: 2 min at $50^{\circ} \mathrm{C}, 10 \mathrm{~min}$ at $95^{\circ} \mathrm{C}$ and 40 cycles of $95^{\circ} \mathrm{C}(15 \mathrm{~s})$, and $60^{\circ} \mathrm{C}(1 \mathrm{~min})$. Reactions were run in an Applied Biosystems (Foster City, CA, U.S.A.) ABI PRISM 7700 sequence detection system, and data were collected at all isothermal stages. Following PCR amplification, threshold detection parameters (baseline and cycle threshold limit) were adjusted manually to optimize the results relative to standard curves obtained by amplification of four 10-fold dilutions of clones of all target sequences. Duplicate samples were quantified for fructose$1,6,-$ bis phosphatase and $\mathrm{H}^{+}$-ATPase and mean values used to express mRNA abundance relative to histone $\mathrm{H} 3$.

\section{ACKNOWLEDGMENTS}

This work was funded by a Biotechnology and Biological Sciences Research Council Cooperative Award in Science and Engineering studentship and Syngenta Ltd. We are grateful to J. Abbot, S. Butcher (Imperial College London), and J. Ribeiro (NIH) for advice and guidance on annotation EST database, and to A. Cleaver and A. Evans (Syngenta Ltd.) for assistance with the Expressionist software.

\section{LITERATURE CITED}

Batish, S., Hunter, A., Ashby, A. M., and Johnstone, K. 2003. Purification and biochemical characterisation of Psp1, an extracellular protease produced by the oilseed rape pathogen Pyrenopeziza brassicae. Physiol. Mol. Plant Pathol. 62:13-20.

Bélanger, R., Bushnell, W. R., Dik, A. J., and Carver, T. L. W., eds. 2002. The Powdery Mildews: A Comprehensive Treatise. American Phytopatholocigal Society Press, St Paul, MN, U.S.A.

Bindschedler, L. V., Sanchez, P., Dunn, S., Mikan, J., Thangavelu, M., Clarkson, J. M., and Cooper, R. M. 2003. Deletion of the SNP1 trypsin protease from Stagonospora nodorum reveals another major protease expressed during infection. Fungal Genet. Biol. 38:43-53.

Bindslev, L., Kershaw, M. J., Talbot, N. J., and Oliver, R. P. 2001. Complementation of the Magnaporthe grisea $\Delta c p k A$ mutation by the Blumeria graminis $p k A-c$ gene: Functional genetic analysis of an obligate plant pathogen. Mol. Plant-Microbe Interact. 14:1368-1375.

Both, M., and Spanu, P. 2004. Blumeria graminis f. sp. hordei, an obligate pathogen of barley. Pages 202-218 in: Plant Pathogen Interactions. N. Talbot, ed. Blackwell publishing, Oxford.

Chaure, P., Gurr, S. J., and Spanu, P. 2000. Stable transformation of Erysiphe graminis, an obligate biotrophic pathogen of barley. Nature Biotech 18:205-207. 
Chomczynsky, P., and Sacchi, N. 1987. Single-step method of RNA isolation by acid guanidium isothiocyanate phenol chloroform extraction. Anal. Biochem. 162:156-159.

Dimopoulos, G., Christophides, G. K., Meister, S., Schultz, J., White, K. P., Barillas-Mury, C., and Kafatos, F. C. 2002. Genome expression analysis of Anopheles gambiae: Responses to injury, bacterial challenge, and malaria infection. Proc. Natl. Acad. Sci. U.S.A. 99:8814-8819.

Francis, S. A., Dewey, F. M., and Gurr, S. J. 1996. The role of cutinase in germling development and infection by Erysiphe graminis f. sp. hordei. Physiol. Mol. Plant Pathol. 49:201-211.

Green, J. R., Carver, T. L. W., and Gurr, S. J. 2002. The formation and function of infection and feeding structures. Pages 66-82 in: The Powdery Mildews: A Comprehensive Treatise. R. Bélanger, W. R. Bushnell, A. J. Dik, and T. L. W. Carver, eds. American Phytopathological Society Press, St Paul, MN, U.S.A.

Grell, M. N., Mouritzen, P., and Giese, H. 2003. A Blumeria graminis gene family encoding proteins with a C-terminal variable region with homologues in pathogenic fungi. Gene 311:181-192.

Hewitt, H. 1998. Fungicides in Crop Protection CAB International, Wallingford, U.K.

Hwang, C. S., Flaishman, M. A., and Kolattukudy, P. E. 1995. Cloning of a gene expressed during appressorium formation by Colletotrichum gloeosporioides and a marked decrease in virulence by disruption of this gene. Plant Cell 7:183-193.

Karpovich-Tate, N., Spanu, P., and Dewey, F. M. 1998. Use of monoclonal antibodies to determine biomass of Cladosporium fulvum in infected tomato leaves. Mol. Plant-Microbe Interact. 11:710-716.

Keniry, C. A., Li, D. H., and Ashby, A. M. 2002. Cloning and expression studies during vegetative growth and sexual development of Psp2, a serine protease gene from Pyrenopeziza brassicae. BBA-Gene Struct. Expr. 1577:159-163.

Kinane, J., and Oliver, R. P. 2003. Evidence that the appressorial development in barley powdery mildew is controlled by MAP kinase activity in conjunction with the cAMP activity. Fungal Genet. Biol. 39:94-102.

Kinane, J., Dalvin, S., Bindslev, L., Hall, A., Gurr, S., and Oliver, R. 2000. Evidence that the cAMP pathway controls emergence of both primary and appressorial germ tubes of barley powdery mildew. Mol. PlantMicrobe Interact. 13:494-502.

Lara-Ortiz, T., Riveros-Rosas, H., and Aguirre, J. 2003. Reactive oxygen species generated by microbial NADPH oxidase NoxA regulate sexual development in Aspergillus nidulans. Mol. Microbiol. 50:1241-1255.

Mitchell, T. K., and Dean, R. A. 1995. The cAMP-dependent protein kinase catalytic subunit is required for appressorium formation and pathogenesis by the rice blast pathogen Magnaporthe grisea. Plant Cell 7:1869-1878

Murphy, J. M., and Walton, J. D. 1996. Three extracellular proteases from Cochliobolus carbonum: Cloning and targeted disruption of alp1. Mol. Plant-Microbe Interact. 9:290-297.

Parisot, D., Dufresne, M., Veneault, C., Lauge, R., and Langin, T. 2002. clap1, a gene encoding a copper-transporting ATPase involved in the process of infection by the phytopathogenic fungus Colletotrichum lindemuthianum. Mol. Genet. Genom. 268:139-151.

Pryce-Jones, E., Carver, T., and Gurr, S. J. 1999. The roles of cellulase enzymes and mechanical force in host penetration by Erysiphe graminis f. sp. hordei. Physiol. Mol. Plant Pathol. 55:175-182.

Quackenbush, J. 2003. Microarrays-Guilt by association. Science 302:240-241.

Rolke, Y., Liu, S. J., Quidde, T., Williamson, B., Schouten, A., Weltring, K. M., Siewers, V., Tenberge, K. B., Tudzynski, B., Tudzynski, P. 2004.
Functional analysis of $\mathrm{H}_{2} \mathrm{O}$-generating systems in Botrytis cinerea: The major $\mathrm{Cu}-\mathrm{Zn}$-superoxide dismutase (BCSOD1) contributes to virulence on French bean, whereas a glucose oxidase (BCGOD1) is dispensable. Mol. Plant Pathol. 5:17-27.

Sambrook, J., Fritsch, E. F., and Maniatis, T. 1987. Molecular Cloning: A Laboratory Manual. Cold Spring Harbor Laboratory Press, Cold Spring Harbor, NY, U.S.A

Schulze-Lefert, P., and Panstruga, R. 2003. Establishment of biotrophy by parasitic fungi and reprogramming of host cells for disease resistance. Annu. Rev. Phytopathol. 41:641-667.

Sims, A. H., Robson, G. D., Hoyle, D. C., Oliver, S. G., Turner, G., Prade, R. A., Russell, H. H., Dunn-Coleman, N. S., and Gent, M. E. 2004. Use of expressed sequence tag analysis and cDNA microarrays of the filamentous fungus Aspergillus nidulans. Fungal Genet. Biol. 41:199-212.

Sterrenburg, E., Turk, R., Boer, J. M., van Ommen, G. B., and den Dunnen, J. T. 2002. A common reference for cDNA microarray hybridizations. Nucleic Acids Res. 30:e116.

Struck, C., Siebels, C., Rommel, O., Wernitz, M., and Hahn, M. 1998. The plasma membrane $\mathrm{H}^{+}$-ATPase from the biotrophic rust fungus Uromyces fabae: Molecular characterization of the gene (pmal) and functional expression of the enzyme in yeast. Mol. Plant-Microbe Interact. 11:458 465.

Thomas, S. W., Rasmussen, S. W., Glaring, M. A., Rouster, J. A., Christiansen, S. K., and Oliver, R. P. 2001. Gene identification in the obligate fungal pathogen Blumeria graminis by expressed sequence tag analysis. Fungal Genet. Biol. 33:195-211.

Thomas, S. W., Glaring, M. A., Rasmussen, S. W., Kinane, J. T., and Oliver, R. P. 2002. Transcript profiling in the barley mildew pathogen Blumeria graminis by serial analysis of gene expression (SAGE). Mol. Plant-Microbe Interact. 15:847-56.

$\mathrm{Xu}$, J.-R. 2000. MAP kinases in fungal pathogens. Fungal Genet. Biol. 31:137-152.

Xu, J.-R., and Hamer, J. E. 1996. MAP kinase and cAMP signaling regulate infection structure formation and pathogenic growth in the rice blast fungus Magnaporthe grisea. Genes Dev. 10:2696-2706.

Xu, J.-R., Urban, M., Sweigard, J. A., and Hamer, J. E. 1997. The CPKA gene of Magnaporthe grisea is essential for appressorial penetration. Mol. Plant-Microbe Interact. 10:187-194.

Xue, C. Y., Park, G., Choi, W. B., Zheng, L., Dean, R. A., and Xu, J.-R. 2002. Two novel fungal virulence genes specifically expressed in appressoria of the rice blast fungus. Plant Cell 14:2107-2119.

Zhang, Z., and Gurr, S. J. 2001. Expression and sequence analysis of the Blumeria graminis mitogen-activated protein kinase genes, $m p k 1$ and mpk2. Gene 266:57-65.

Zhang, Z., Priddey, G., and Gurr, S. 2001. The barley powdery mildew protein kinase $\mathrm{C}$ gene, $p k c 1$ and $p k c$-like gene, are differentially expressed during morphogenesis. Mol. Plant Pathol. 2:327-337.

\section{AUTHOR-RECOMMENDED INTERNET RESOURCES}

Broad Institute Fungal Genome Initiative website: www.broad.mit.edu/annotation/fungi/fgi

Broad Institute Magnaporthe grisea database: www.broad.mit.edu/annotation/fungi/magnaporthe

Broad Institute Fusarium graminearum database: www.broad.mit.edu/annotation/fungi/fusarium

The COGEME phytopathogenic fungi and oomycete EST database: cogeme.ex.ac.uk/ 